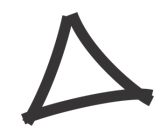

Revista Triângulo

ISSN 2175-1609

\title{
ALFABETIZAÇÃO DE ALUNOS COM DEFICIÊNCIA INTELECTUAL: UM ESTUDO SOBRE ESTRATÉGIAS DE ENSINO UTILIZADAS NO ENSINO REGULAR
}

\author{
LITERACY OF STUDENTS WITH INTELLECTUAL DISABILITIES: A STUDY ON TEACHING \\ STRATEGIES USED IN REGULAR EDUCATION
}

\author{
ALFABETIZACIÓN DE ALUMNOS CON DISCAPACIDAD INTELECTUAL: UN ESTUDIO SOBRE \\ ESTRATEGIAS DE ENSEÑANZA UTILIZADAS EN LA ENSEÑANZA REGULAR
}

\author{
Mirian Célia Castellain Guebert \\ Pontifícia Universidade Católica do Paraná - PUCPR \\ E-mail: mirian.castellain@pucpr.br
}

\begin{abstract}
RESUMO
Com o advento do processo inclusivo na educação, o qual prevê a escolarização da pessoa independe de suas características individuais. O estudo tem por finalidade identificar quais estratégias de ensino são desenvolvidas por professores alfabetizadores para que alunos com diagnósticos de deficiência intelectual aprendam a ler e escrever. Este trabalho tem como objetivo buscar identificar quais são as estratégias desenvolvidas por professores do Ensino Fundamental no ensino regular. Trata-se de uma pesquisa qualitativa que para a coleta dos dados foi utilizado a observação direta em sala de aula do terceiro ano do ensino fundamental de uma escola reconhecida pela qualidade expressa em seus processos pedagógicos, sendo a instituição privada e localizada na capital do estado do Paraná. As análises dos dados aferiram dois eixos: a adaptação das atividades com relação ao estudante com deficiência intelectual; a relação do conteúdo/forma trabalhados e o rendimento do aluno. Neste trabalho, foram tecidas discussões a luz das teorias de Bernstein (1988), Ferreiro (1992) e Vigotski (1994). Os resultados identificam que as práticas desenvolvidas pelo professor observado não atendem às diferentes formas de aprendizagens dos discentes, que implica num déficit nos processos de construção da leitura e escrita que comprometem a escolarização dos aprendizes, especialmente do aluno com deficiência intelectual.
\end{abstract}

PALAVRAS-CHAVE: Práticas Docentes. Alfabetização. Deficientes intelectuais.

\section{ABSTRACT}

With the advent of the inclusive process in education, which provides for the schooling of the person independent of their individual characteristics. This study aims to identify which teaching strategies are developed by literacy teachers so that students with diagnoses of intellectual disabilities learn to read and write. This work aims to identify the strategies developed by elementary school teachers in regular education. It is a qualitative research that used the direct observation in the classroom of the third year of elementary school of a school recognized for the quality expressed in its pedagogical processes, being the institution private and located in the capital of the state of Paraná. The analysis of the data verified two axes: the adaptation of the activities with respect to the student with intellectual disability; the relation of the content / form worked and the income of the student. In this work, discussions were woven in light of the theories of Bernstein (1988), Ferreiro (1992) and Vigotski (1994). The results identify that the practices developed by the observed teacher do not attend the different forms of learning of the students, which implies a deficit in the processes of reading and writing that compromise the schooling of the learners, especially the student with intellectual disability.

KEYWORDS: Teaching Practices. Literacy. Intellectual handicapped.

\section{RESUMEN}

Con la llegada del proceso inclusivo en la educación, que proporciona la educación del individuo independientemente de sus características individuales. Este estudio tiene como objetivo identificar las estrategias 
de enseñanza desarrolladas por los profesores de alfabetización para que los estudiantes con un diagnóstico de discapacidad intelectual aprendan a leer y escribir. Este trabajo tiene como objetivo identificar las estrategias desarrolladas por los maestros de escuela primaria en la educación regular. Esta es una investigación cualitativa para la recolección de datos ha sido uso la observación directa en la clase de tercer grado de la escuela primaria en una escuela reconocida por la calidad expresada en sus procesos educativos e institución privada, ubicada en la capital del estado de Paraná. El análisis de los datos verificó dos ejes: la adaptación de las actividades en comparación con el estudiante con discapacidad intelectual; la relación del contenido / formulario trabajado y el ingreso del estudiante. En este trabajo, las discusiones han sido tejidas a partir de las teorías de la luz Bernstein (1988), Smith (1992) y Vigotski (1994). Los hallazgos resaltan que las prácticas desarrolladas por el docente observado no responderían a las diferentes formas de aprendizaje de los estudiantes, lo que implicaría un déficit en la lectura y escritura de los procesos de construcción que comprometen la educación de los estudiantes, especialmente los estudiantes tener una discapacidad intelectual.

PALABRAS CLAVE: Prácticas de enseñanza. Alfabetización Discapacidad intelectual.

\section{INTRODUÇÃO}

Na busca de compreender as práticas que estão sendo desenvolvidas, por professores alfabetizadores, que atuam em escolas regulares com pessoas acometidas pela deficiência intelectual, esta pesquisa teve por finalidade identificar quais as estratégias de ensino utilizadas por professores de alunos diagnosticados com deficiência intelectual incluídos em sala de aula no ensino fundamental que estão em processo de alfabetização.

A opção em estudar as estratégias utilizadas pelos docentes para ensinar deficientes intelectuais na escola regular, dá-se pelo fato de considerar que a deficiência intelectual é caracterizada pelo atraso significativo em seu processo cognitivo, e que, autores consagrados como Carvalho (2004), Pacheco (2007), González (2008), quanto às recomendações oficiais (Brasil, 1997; Brasil, 1998; Brasil, 2007) indicam que, para um rendimento escolar satisfatório, esses alunos necessitam de estratégias, bem como a organização curricular diferenciadas, podendo essas utilizar de adaptações curriculares que considerem as características cognitivas dos alunos.

A Declaração de Salamanca (1994) reconhece a possibilidade de todos aprenderem juntos, numa escola que providenciar a aprendizagem de seus estudantes. O documento também considera fundamental a participação dos pais, a formação dos professores e as organizações das pessoas com deficiência na pronta identificação de como aprender melhor e por quais estratégias de intervenção atendem as necessidades educacionais nas escolas integradoras, no Brasil denominadas inclusivas.

Tanto a Declaração de Salamanca (1994), quanto a LDBEN (BRASIL, 1996), não determinam a obrigatoriedade de atendimento no ensino regular para pessoas com deficiências,

\begin{tabular}{l|l|l|l|l|l} 
(C) Rev. Triang. & Uberaba, MG & v.11 & n.2 & p. 280-299 & Maio/Ago. 2018
\end{tabular}




\section{Revista Triângulo}

ISSN 2175-1609

embora definam que a inclusão de alunos com necessidades educacionais especiais no ensino regular, seja a forma preferencial nas escolas regulares, os documentos reconhecem que a inclusão escolar demanda modificações intensas na política educacional.

Não se pode negar que um dos aspectos enfatizados é a modificação da organização escolar refletida nas práticas pedagógicas desenvolvidas no interior das escolas para que todos possam aprender independentemente de suas características. Os documentos indicam que as necessidades educativas especiais devem incorporar uma "pedagogia centrada no aluno", logo as organizações escolares devem efetuar adaptações necessárias para cada discente com o objetivo que tenham sucesso em sua vida acadêmica. Para tanto, os programas de ensino devem ser adaptados às necessidades dos alunos e não o contrário e, por consequência, as escolas devem propiciar opções curriculares que atendam aos diferentes interesses e necessidades.

O documento denominado Parâmetros Curriculares Nacionais - Adaptações Curriculares, publicado pelo MEC em 1998, a partir do que considera como "significativas experiências pedagógicas desenvolvidas no país", indica providências e recomendações a serem utilizadas pelo sistema escolar brasileiro, objetivando a qualidade no processo de escolarização de todos os alunos (BRASIL. MEC, 1998). Em primeiro lugar, na perspectiva de "Educação Para Todos", recomenda-se que a escola deva enfrentar o desafio de "garantir o acesso e a apropriação do saber, com vistas a atingir as finalidades da educação escolar”. Enfatiza, ainda, que há necessidade de concretizar o caráter de flexibilidade e dinamização do currículo escolar além de que favoreça a interatividade e a eficiência que necessita ser alcançada por todos os estudantes e pela escola (BRASIL. MEC, 1998).

Nessa perspectiva, a escola tem como função desenvolver práticas que apontem meios às necessidades específicas dos estudantes, não sendo um tratamento diversificado dentro do mesmo currículo, por meio do respeito a diversidade, mantendo a ação pedagógica para que todos os alunos possam aprender juntos. O documento considera que a aprendizagem escolar está diretamente vinculada ao currículo, organizado para orientar os níveis de ensino e as ações docentes.

Dessa forma, as orientações oficiais recomendam que é necessário a escola regular modificar não apenas as atitudes e expectativas em relação a esses alunos, mas organizarem-se para constituir uma escola real, que dê conta das especificidades dos alunos. Logo promoverão 
o desenvolvimento integral e a aprendizagem por meio da flexibilização curricular com a identificação das necessidades pedagógicas e com rede de apoio que favoreça o processo educacional.

Essa flexibilidade curricular constitui possibilidades de atuar frente às dificuldades de aprendizagem dos estudantes. Não se trata de um novo currículo, mas sim um currículo “dinâmico, com planificações pedagógicas e ações eficazes dos docentes", tendo como critérios para essa adaptação: o que o aluno deve aprender; como e quando aprender; que formas de organização do ensino são mais eficientes para o processo de aprendizagem; como e quando avaliar o aprendiz (BRASIL. MEC, 1998, p.33).

Entendendo o processo de educação como uma prática social, e a escolarização sendo uma necessidade cultural, esse processo deve ser organizado para atender as características dos estudantes por meio de estratégias que viabilizem a aprendizagem como resultados de um processo de mediação junto a todos os alunos.

Outro aspecto a ser considerado ao planejar as atividades a serem desenvolvidas com estudantes com deficiência são os trabalhos simultâneos, cooperativos e participativos; respeitando o grau de intensidade da programação curricular chamadas de rede de apoio. Nesse sentido, a definição das adaptações curriculares "carregadas de significados" constituírem modificações pequenas no currículo facilmente realizadas pelos professores no planejamento das atividades, além de constituírem ajustes do contexto normal da sala de aula, considerando que é fundamental o aluno aprender o conteúdo elaborado para que a escola cumpra com sua função social e curricular para que os envolvidos possam obter sucesso em sua escolarização (BRASIL. MEC, 1998).

Essas modificações englobam o planejamento e a atuação do docente, selecionando, organizando e introduzindo estratégias específicas, assim como realizar alterações didáticas organizando ações diferenciadas em sala de aula que devem respeitar as características de cada aprendiz em seu processo de escolarização.

O professor ao considerar que o currículo é vivo, esse deve se envolver com diferentes formas de ensinar e de avaliar os diferentes conteúdos e, para isso, as adaptações metodológicas devem ser realizadas situando o aluno no grupo a que pertence, por meio da adoção de métodos e técnicas de ensino específicas, apoiados nos recursos físicos para realização das atividades 


\section{Revista Triângulo}

ISSN 2175-1609

propostas, estas devem favorecer o trabalho cooperativo com chances iguais de execução, já que o processo se diz inclusivo.

A adaptação curricular só se concretizará, partindo-se da premissa de um currículo funcional quando aprendizagem ocorrer de forma gradual, significativa e sistematizada, para que a escola proporcione a todos aprender juntos. São necessárias medidas pedagógicas possíveis de serem adotadas, que visam reflexões e atitudes educacionais, para que os alunos com deficiência intelectual possam aprender no contexto da escola regular.

Para garantir um processo de escolarização, faz-se necessário que os professores realizem escolhas metodológicas e definam quais os recursos didáticos relevantes para a realização do trabalho coletivo considerando também as características dos estudantes com deficiência em processo de escolarização (BRASIL. MEC, 2007).

As escolhas representam a busca de soluções e, nesse sentido, da adaptação de currículos e de atividades para o processo avaliativo são considerados quando se referem aos alunos com deficiência intelectual.

Ao assumirem o caráter substitutivo da educação especial, as práticas adaptativas funcionam como reguladores externos para as aprendizagens, ao estarem subsidiadas por procedimentos de ensino, que buscam atender à necessidade dos educandos com deficiência intelectual, submetendo-os aos processos de escolarização.

Como se percebe, ambos os documentos recomendam que as estratégias desenvolvidas pelos professores em sala de aula garantam que todos os alunos aprendam independente de suas características, dentre eles aqueles caracterizados como deficientes intelectuais.

Por outro lado, as recomendações oriundas do Ministério da Educação (BRASIL. MEC, 1998; BRASIL. MEC, 2007), quando propuseram as adaptações curriculares e os procedimentos didáticos como uma possibilidade aos estudantes com deficiência intelectual, permaneceram no âmbito geral, sem qualquer detalhamento mais preciso que ofereça aos professores subsídios para definir "o que fazer" efetivamente no sentido de propiciar meios para que esses estudantes aprendam na escola regular.

Para Carvalho (2004), o que necessita ser modificado no processo de escolarização é a postura dos profissionais frente à deficiência, que levem em conta as características individuais, 
principalmente os alunos que apresentam algum tipo de necessidade específica. No entanto, cabe à escola a responsabilidade de garantir o processo de aprendizagem para todos os educandos, respeitando as diferenças que implicam no seu reconhecimento com base na percepção do outro como sujeito da aprendizagem.

Porém, o reconhecimento das diferenças nos processos de aprendizagem envolve inúmeras e complexas barreiras existentes na organização do processo de escolarização, de forma significativa, sendo de cunho atitudinal, procedimental e conceitual, mas também "no currículo e nas adaptações curriculares, na avaliação continua do trabalho, na intervenção psicopedagógico e na qualificação da equipe de educadores". (CARVALHO, 2004, p.77).

Ao estabelecer relação entre o não saber e o saber elaborado, entre o planejamento e as práticas pedagógicas, as adaptações curriculares não devem ser entendidas como um conjunto de conhecimentos que devem ser transmitidos pela escola aos alunos, mas como um conjunto de experiências que a escola, como instituição formal, dispõe aos discentes para potencializar a aprendizagem e desenvolvimento.

Nesse sentido, para Carvalho (2000), as adaptações curriculares são encaradas como as modificações realizadas pelos professores, de um lado intencionalmente organizadas e, por outro, de forma quase que espontânea a dinâmica de ações que envolvem a prática docente na sala de aula, visando responder às necessidades de cada estudante. Um currículo flexível e aberto às adaptações é condição fundamental para a atender as necessidades educativas de qualquer aprendiz em condição sine qua non para equalização das oportunidades a todos que buscam a escola de qualidade.

Todas essas orientações parecem demonstrar que, para a aprendizagem do conteúdo escolar ser acessível ao aluno com deficiência intelectual, é preciso que ocorram adaptações didáticas que considerem as dificuldades inerentes aos seus déficits intelectuais. Nessa perspectiva, considerando a aprendizagem da língua escrita como um dos requisitos básicos para a progressão a níveis mais altos de escolaridade, constata-se a necessidade de identificar as estratégias utilizadas por professores no processo de alfabetização de estudantes com deficiência intelectual. 


\section{REFERENCIAL TEÓRICO}

Embora nas vertentes da Psicologia (como as da Psicologia genética e a sócio histórica), que se a preocupação com a escolarização de pessoas com deficiência intelectual date dois séculos, foi a partir da metade do século XX que surgiram iniciativas concretas que visavam o acesso ao saber escolar por esses alunos, especialmente apoiadas contrapuseram às perspectivas teóricas que consideravam a inteligência como inata e com limitações irreversíveis.

Em oposição à escolarização de alunos com deficiência intelectual tradicionalmente desenvolvida por meio de processos distintos de ensino (escola e classes especiais), a partir dos anos 1970, iniciou-se em todo o mundo o movimento em prol da absorção desses alunos pelo ensino regular, que redundou em uma abordagem inclusiva decorrente da Declaração de Salamanca, que recomendou:

\footnotetext{
"Promover el objetivo de la Educación para Todos examinando los cambios fundamentales de política necesarios para favorecer el enfoque de la Educación integradora, concretamente capacitando a las escuelas para atender a todos los niños, sobretudo a los que tienen necesidades educativas especiales" (CONFERENCIA MUNDIAL SOBRE NECESIDADES EDUCATIVAS ESPECIALES, 1994, p. III).
}

Em relação ao direito de acesso ao ensino regular os alunos com necessidades educacionais especiais (entre eles alunos com deficiência intelectual, foco deste trabalho), a declaração considera essencial que os países deem "a mais alta prioridade política e orçamentária à melhoria de seus sistemas educativos para que possam incluir a todas as crianças, independentemente de suas diferenças ou dificuldades individuais" (CONFERENCIA MUNDIAL SOBRE NECESIDADE EDUCATIVAS ESPECIALES, 1994, p. IX).

Isto é, a Declaração de Salamanca reconhece que a inclusão de alunos com necessidades educacionais especiais exige uma planificação adequada e pesados investimentos, que garantam o acesso ao ensino com qualidade aos alunos historicamente excluídos da escola por políticas educacionais elitistas e seletivas.

Nesse sentido, a Declaração recomenda que o poder público adote, em caráter de lei e como política, o princípio de educação integradora, que "permita matricular a todos em escolas regulares, a não ser que existam razões de peso para o contrário" (CONFERENCIA MUNDIAL 
SOBRE NECESSIDADES EDUCATIVAS ESPECIALES, 1994, p. IX). Essa ressalva na Declaração em relação à inclusão escolar tem sido objeto polêmico entre educadores e estudiosos, à medida que abre espaço para que nem todos os alunos com necessidades educacionais especiais sejam matriculados no ensino regular.

Tal como a Declaração, a atual Lei de Diretrizes e Bases da Educação Nacional LBDEN - em seu Artigo 58, embora não determine que as pessoas com deficiências devam ser atendidas obrigatoriamente nas escolas comuns, define que a inclusão de alunos com necessidades educacionais especiais no ensino regular seja a forma mais adequada e preferencial de educação escolar: "Entende-se por educação especial, para efeitos desta lei, a modalidade de educação escolar oferecida preferencialmente na rede regular de ensino, para educandos portadores de necessidades especiais" (BRASIL, 1996).

Se é verdade que tanto a Declaração de Salamanca quanto a LDBEN reconhecem que a inclusão escolar demanda modificações intensas na política educacional, não se pode negar que um dos aspectos enfatizados é a modificação na organização escolar, refletida nas práticas pedagógicas desenvolvidas no interior das escolas, para que todos possam aprender.

Para se garantir o acesso ao currículo para os alunos com deficiência intelectual, o referido documento enfatiza a necessidade de estratégias utilizadas em sala de aula que favoreçam a aprendizagem e possibilitem o desenvolvimento das habilidades adaptativas sociais e de comunicação, do cuidado pessoal, da autonomia e da apropriação do conhecimento elaborado.

Além disso, considera que o currículo vivo implica em formas de ensinar e avaliar os diferentes conteúdos e, para isso, as adaptações metodológicas devem ser realizadas situando o aluno no grupo a que pertence, por meio da adoção de métodos e técnicas de ensino específicas, com a utilização de recursos físicos para realização das atividades propostas que favoreçam o trabalho cooperativo, com possibilidades iguais de execução.

Ao considerar que a adaptação curricular só se concretizará partindo-se da premissa de um currículo funcional, em que a aprendizagem ocorra de forma gradual, significativa e sistematizada, para que a escola possibilite que todos aprendam juntos, estas são as medidas pedagógicas possíveis de serem adotadas, que visam o atendimento das necessidades 
educacionais, para que os alunos com características diferentes possam aprender. embora todas essas orientações demonstrem que para que a aprendizagem do conteúdo escolar seja acessível a alunos com deficiência intelectual e que é preciso que ocorram adaptações didáticas que levem em consideração as dificuldades inerentes aos déficits intelectuais, não se chega ao nível concreto das práticas pedagógicas desenvolvidas em sala de aula.

Se a aprendizagem da língua escrita é um dos requisitos básicos para a progressão a níveis mais altos de escolaridade, ela deveria receber prioridade dos sistemas escolares e das escolas.

Ocorre que, mesmo em relação ao significado do conceito alfabetização, muitas são as controvérsias existentes.

O trabalho fundamental de Emília Ferreiro (1992) mostra-nos que duas são as concepções de alfabetização: aquelas que encaram a língua escrita como um código da língua oral; e os que embora não desprezem o fato de ela ser construída com base no acervo oral, entendem-na como uma forma de representação que implica na aquisição de habilidades e competências diferentes.

Ferreiro (1992, p. 12) alerta para uma característica básica de qualquer código, a de que "tanto os elementos como as relações já estão predeterminados; o novo código não faz se não encontrar uma representação diferente para os mesmos elementos e as mesmas relações", dando como exemplo o código Morse, em "que todas as configurações gráficas que caracterizam as letras se convertem em sequências de pontos e traços, mas a cada letra corresponde uma configuração diferente de pontos e traços, em correspondência biunívoca".

Diferentemente, uma forma de representação implica que nem todos os elementos e relações contidos em uma forma de representação estejam presentes em nova forma de representação.

Para ela, portanto, a língua escrita não mantém uma relação biunívoca com os elementos componentes da língua oral, envolvendo praticamente todos os elementos de cada uma dessas duas formas distintas de representação: fonema x grafema; segmentação das palavras orais e 


\section{Revista Triângulo}

ISSN 2175-1609

escritas; impossibilidade de transcrição ipsis literis das distinções emocionais das expressões escritas (entonação), etc.

Para Ferreiro (1992, p. 12), a "invenção da escrita foi um processo histórico de construção de um sistema de representação, não um processo de codificação" e, portanto, conceber a escrita como uma compreensão do modo de construção dos sistemas de representação é entender o porquê de algumas características de linguagem oral não serem retidas nas representações escritas; logo, sua aprendizagem converte-se em apropriação de um novo objeto do conhecimento.

Essas duas formas de se conceber a linguagem escrita têm consequências decisivas para a ação do alfabetizador, segundo Ferreiro.

Ao conceber a escrita como código de transcrição que converte as unidades sonoras em unidades gráficas, coloca-se em primeiro plano a discriminação perceptiva nas modalidades envolvidas (visual e auditiva).

Os programas de preparação para a leitura e a escrita que derivam dessa concepção centram-se, assim, na exercitação da discriminação, sem se questionarem jamais sobre a natureza das unidades utilizadas. Para ela, portanto, se a escrita for concebida como um código, a sua aprendizagem implica na aquisição de uma técnica.

A linguagem, como tal, é colocada de certa forma entre parênteses, ou melhor, reduzida a uma série de sons (contrastes sonoros em nível do significante).

Mas se a aprendizagem da língua escrita é concebida como a compreensão do modo de construção de um sistema de representação, “[...] [o fato de se] falar adequadamente e [se fazer] todas as discriminações perceptivas [...] não resolve o problema central: compreender a natureza desse sistema de representação" (FERREIRO, 1992 p. 14-15).

Para ela, por fim, se a escrita for concebida como código, a sua aprendizagem implica na aquisição de uma técnica.

Soares (1998) também oferece contribuição importante em relação ao processo de aquisição da língua escrita quando distingue alfabetização de letramento. Segundo a autora, o 
termo letramento é uma tradução para o português da palavra inglesa literacy, tendo sido utilizado pela primeira vez por Kato (1986), cuja conceituação foi realizada por Tfouni (1988):

Alfabetização refere-se à aquisição da escrita enquanto aprendizagem de habilidades para leitura, escrita e as chamadas práticas de linguagem. Isto é levado a efeito, em geral, por meio do processo de escolarização e, portanto, da instrução formal. A alfabetização pertence, assim, ao âmbito do individual.

O letramento, por sua vez, focaliza os aspectos sociohistóricos da aquisição da escrita. Entre outros casos, procura estudar e descrever o que ocorre nas sociedades quando adotam um sistema de escritura de maneira restrita ou generalizada: procura ainda saber quais práticas psicossociais substituem as práticas "letradas" em sociedades ágrafas.

Há uma diferença entre saber ler e escrever (ser alfabetizado) e viver na condição ou estado de quem sabe ler e escrever (ser letrado). Ou seja, uma pessoa que aprende a ler e a escrever, que se torna alfabetizada, só se torna letrada quando passa a fazer uso da leitura e da escrita ao envolver-se com práticas sociais de leitura e de escrita; é diferente de uma pessoa que, ou não sabe ler e escrever porque é analfabeta, ou porque, sabendo ler e escrever, não faz uso da leitura e da escrita, ou seja, que é alfabetizada, mas não é letrada, não vive no estado ou condição de quem sabe ler e escrever e pratica a leitura e a escrita.

Para Soares (1998), a pessoa letrada não é a mesma, social e culturalmente, do que quando era analfabeta ou iletrada, pois passa a ter outra condição social e cultural. Não se trata propriamente de mudar de nível ou de classe social, mas de mudar seu lugar social, seu modo de viver na sociedade, sua inserção na cultura, suas relações interpessoais, as relações com o contexto, com os bens culturais, o torna diferente.

Portanto, a diferença entre alfabetização e letramento é que o alfabetizado se caracteriza como aquele indivíduo que sabe ler e escrever; enquanto um indivíduo letrado é aquele que vive em estado de letramento, isto é, não só sabe ler e escrever, mas usa socialmente de forma adequada a leitura e a escrita para atender às demandas sociais:

Letramento é o estado ou condição de indivíduos ou de grupos sociais de sociedades letradas que exercem efetivamente as práticas sociais de leitura e de escrita, participam competentemente de eventos de letramento. (SOARES, 2002, p. 145). 


\section{Revista Triângulo}

ISSN 2175-1609

Sob a base teórica de Vigotski (1997), que considera que o desenvolvimento precede a aprendizagem (tal como Piaget indicava), por outro, dialeticamente, a aprendizagem também exerce influência sobre o desenvolvimento.

Nessa perspectiva, Vigotski (1997) elaborou o conceito de "zona de desenvolvimento proximal" - dentro da qual as crianças solucionariam desafios cognitivos que iriam desde aqueles solucionados com apoio e ajuda externa (nível de desenvolvimento proximal), por meio de interações sociais, até que eles construíssem possibilidades de resolução autônoma (nível de desenvolvimento real).

Vigotski (1989), tratando a deficiência globalmente, postula que o defeito é constituidor de uma estrutura psicológica que se iniciaria a partir do momento em que o indivíduo mantivesse relações sociais significativas, provocadoras de reações que viessem a compensar a sua deficiência de alguma forma.

Para Vigotski (1997), tanto as crianças com deficiência quanto as normais deveriam ter a educação de forma integrada, pois, dessa forma, poder-se-ia contribuir para o desenvolvimento dessas últimas por meio da compensação e da correção de erros.

Ao fazer a crítica dos métodos psicológicos de investigação da criança anormal em vigência na sua época, que se baseava numa concepção puramente quantitativa e biológica do desenvolvimento infantil, esse autor retirou implicações em relação aos processos escolares: "Enquanto na teoria o problema se reduzia a um desenvolvimento quantitativamente limitado e de proporções diminuídas, na prática, se promoveu a ideia de um ensino reduzido e mais lento" (Vigotski, 1997, p. 12).

Essa nova perspectiva serviu de base para que o autor considerasse que a deficiência intelectual não poderia ser identificada apenas com base no seu nível de desenvolvimento real, mas, ao contrário, os processos de interação deveriam fazer parte integrante dessa caracterização, já que seriam intrínsecos ao próprio desenvolvimento cognitivo dos sujeitos:

A defectologia está lutando agora pela tese básica cuja defesa vê a única garantia de sua existência como ciência, qual seja: a criança cujo desenvolvimento se vê complicado pelo defeito não é simplesmente uma criança menos desenvolvida que 
seus coetâneos normais, mas uma criança que se desenvolveu de outro modo. (VIGOTSKI, 1997, p. 12).

Nesse sentido, a abordagem compensatória, que leva em conta a dificuldade, mas também a eficiência das estratégias pedagógicas utilizadas para ajudar a superar o problema, foi defendida por Vigotski (1997). Por isso, enfatizou que as consequências da deficiência no desenvolvimento da fala e do pensamento seriam secundárias ao considerar que partes das dificuldades originárias da deficiência poderiam ser superadas por uma pedagogia compensatória.

Além disso, com base em observações de crianças com deficiência, Vigotski (1997) concluiu que as deficiências intelectuais não são as únicas responsáveis pelo rebaixamento cognitivo. Para ele, existem outros fatores que poderiam estar influenciando, entre eles, a desmotivação. Tendo em vista que a criança com deficiência intelectual apresenta um comportamento baseado na relação de escolha "este ou aquele" - a qual se estende tanto ao aspecto cognitivo quanto ao afetivo - o ensino calcado somente no seu nível de desenvolvimento real (resultado de testes, por exemplo) não promoveria a relativização de seus pontos de vista e a realização de generalização a partir de conceitos ou vivências.

Desse modo, ao contrário do que determinavam as teorias psicológicas em voga, a ênfase pedagógica deveria residir nas atividades que exigissem abstração e que possibilitassem maior flexibilidade, com vistas à transformação qualitativa das capacidades cognitivas.

Essa perspectiva teórica fornece elementos importantes para a modificação das práticas sistemáticas e rotineiras que caracterizavam a educação de alunos com deficiência intelectual, pois indicam a prática pedagógica como processo de mediação que, tendo como base o nível de desenvolvimento real dos alunos, deveria adotar estratégias de ensino em que a aprendizagem mediada socialmente constituísse parte integrante do processo de construção cognitiva dos sujeitos.

Assim, a perspectiva de Ferreiro (1992) de considerar a língua como forma de representação; a de Soares (1998), da distinção entre a alfabetização e letramento; e a de Vigotski (1987; 1997) servirão de base para análise das práticas pedagógicas selecionadas. 


\section{MATERIAIS E MÉTODOS}

A pesquisa implicou em coleta de dados sobre a prática docente para identificar as estratégias de ensino utilizadas por educadores alfabetizadores em suas salas de aulas.

Devido ao dinamismo de uma aula, optou-se por utilizar a observação direta com registro por meio de gravações, que seguiram a seguinte sistemática: a) Duas gravações semanais de 30' das atividades desenvolvidas pelo professor, por meio da técnica de "Plano Geral (PG)" (BRASIL, MENMOCINE, 2010); b) Transcrição das gravações, registrando-se, especialmente, as estratégias utilizadas pela professora; c) Organização do material coletado por meio de categorias a posteriori (BARDIN, 1994), que congregaram as estratégias e as práticas de ensino.

Os dados coletados foram analisados a partir das categorias estabelecidas para cotejamento em dois eixos: atividades para os alunos e a relação entre conteúdo-forma. Em cada categoria, procurou-se identificar a estratégia de ensino predominante nas práticas pedagógicas desenvolvidas em sala de aula.

Os dados foram descritos considerando: a) a cena; b) a prática da professora e a identificação da estratégia predominante, como podem ser verificados nas cenas abaixo.

\section{ANÁLISE DOS DADOS E RESULTADOS}

\section{Cena 1:}

A turma responde as atividades que foram previamente descritas no quadro, as quais foram lidas e explicadas pela professora. A atividade proposta tivera como o objetivo interpretar o texto lido pela turma em conjunto. No quadro, três questões estavam escritas, referentes ao texto. Foi solicitado aos alunos responderem as questões em seus cadernos.

A professora mantém sob seu controle as ações a serem desenvolvidas pelos educandos, como estratégia, identificou-se a cópia e a releitura do texto para atender ao solicitado 
evidenciando a interpretação da pergunta relacionando-a às informações obtidas na leitura do texto.

A atividade proposta contraria a recomendação oficial de que as atividades devem ser colaborativas, negando também a teoria de Vigotski ao potencializar desenvolvimento e aprendizagem por meio da linguagem e da interação. A prática docente expressa um modelo de planejamento que privilegia o conteúdo, não se preocupando com as diferentes formas de aprender de seus alunos. Não há nenhuma adaptação curricular evidenciada ou adequação dos processos metodológicos.

\section{Cena 2:}

A aula inicia com a solicitação da professora aos seus discentes para se organizarem em duplas. A docente retomou a organização das tarefas, relendo o que estava escrito no quadro, a organização do dia, assinalando as atividades que já haviam realizado, assim como o que ainda precisavam fazer.

A professora realiza diariamente a hora do conto. Essa, inicia a leitura de um capítulo do livro que foi selecionado pela turma no início do semestre. Ao terminar a leitura, solicitou aos alunos que escrevessem um texto a partir da leitura realizada, orientou a turma para terem ótimas ideias dizendo que ajudaria com um banco de palavras, que escreveu no quadro.

Os estudantes iniciam suas produções. Um estudante perguntou à professora se poderia iniciar o texto com um personagem falando, a docente aproveitou a questão para explicar o uso do travessão e letras maiúsculas apresentando as regras da Língua Portuguesa.

Nessa cena, o fato da orientadora retomar a atividade lembrando o que deveriam fazer percebe-se que evidencia a contextualização e favorece a relação da teoria e prática quando relaciona os conceitos gramaticais e sua utilização nas produções realizadas pelos alunos. Porém utiliza da oralidade e demonstração da escrita para os estudantes, não avançando sobre a função da escrita, esclarecendo apenas a necessidade em utilizar de forma adequada às regras da língua portuguesa nas produções dos aprendizes, negando o que entendido por alfabetização.

Para Ferreiro (1995), a escrita pode ser considerada uma representação da linguagem quando envolve um processo de diferenciação dos elementos e relações reconhecidas no objeto 
a ser apresentada, como também uma seleção dos elementos e relações que serão retidos na representação que podem ser analógicas e arbitrárias.

A escrita quando concebida como um código de transcrição que transforma as unidades sonoras em unidades gráficas, coloca-se a percepção visual e auditiva em evidência, logo sua aprendizagem não pode ser mecânica, ou que se considerem somente os aspectos gráficos dessas produções.

Nesse sentido, as produções realizadas pelos alunos devem ser entendidas como resultados do processo de construção de significados de códigos que unificam a linguagem escrita, possibilitando aprendizagem e desenvolvimento do processo de alfabetização.

Tfouni (1988, p. 9) define:

Alfabetização refere-se à aquisição da escrita enquanto aprendizagem de habilidades para leitura, escrita e as chamadas práticas de linguagem. Isto é levado a efeito, em geral, por meio do processo de escolarização e, portanto, da instrução formal. A alfabetização pertence, assim, ao âmbito do individual. O letramento, por sua vez, focaliza os aspectos sociohistóricos da aquisição da escrita. Entre outros casos, procura estudar e descrever o que ocorre nas sociedades quando adotam um sistema de escritura de maneira restrita ou generalizada: procura ainda saber quais práticas psicossociais substituem as práticas "letradas" em sociedades ágrafas.

Há diferenças diferença entre: não saber ler e escrever, ser analfabeta; saber ler e escrever, ser alfabetizado; viver na condição ou estado de quem sabe ler e escrever, ser letrado. Ao não sabe ler e escrever é denominada analfabeta, contudo, sabendo, apenas, ler e escrever, é classificado como alfabetizada, mas, somente, ao conseguir realizar o uso da leitura e da escrita nas práticas contextualizadas socialmente, torna-se letrada.

Assim, embora alfabetizar e letrar sejam duas ações diferentes, não devem ser encaradas como completamente dicotômicas. O ideal é alfabetizar letrando, ou seja, por meio de contextos das práticas sociais da leitura e da escrita, de modo que o indivíduo desenvolva-se sendo alfabetizado e letrado, ao mesmo tempo.

O processo de letramento envolve dois fenômenos bastante diferentes, a leitura e a escrita, sendo, cada um deles, constituído de uma multiplicidade de habilidades, 
comportamentos e conhecimentos. Nessa perspectiva, a leitura caracteriza-se por um conjunto de habilidades e comportamentos, desde simplesmente decodificar sílabas ou palavras, até ler uma obra completa. A escrita implica num conjunto de habilidades e comportamentos que partem da simplicidade de escrever o próprio nome ao escrever uma tese de doutorado, sendo assim, uma pessoa pode ser capaz de escrever, mas não ser apto a escrever uma argumentação defendendo um ponto de vista.

Segundo Soares (1998), há duas condições indicadas para que esse processo se concretize, a primeira condição é que haja escolarização real e efetiva e o acesso à escolaridade se amplie para se ter mais pessoas saberem ler e escrever e, com a extensão da permanência na escola, pudéssemos almejar um pouco mais do que simplesmente a mera alfabetização, mas um processo efetivo de letramento.

A segunda condição é que haja disponibilidade de material de leitura e material impresso posto à disposição: livrarias, preço acessível de livros, dos jornais e revistas, ampliação do número de bibliotecas, além de uma transformação efetiva das práticas desenvolvidas pelas escolas.

Em relação ao processo de alfabetização de alunos com deficiência, poder-se-ia argumentar, como aspecto relevante que não diferem da aquisição da leitura e da escrita para os demais educandos, perspectivas teóricas como as de Vigotski (1994) que se opõem à perspectiva rígida da deficiência intelectual como impeditiva para a aprendizagem acadêmica de estudantes com deficiência intelectual.

Para Vigotski (1994) a escrita ocupou um lugar restrito na prática escolar em relação ao papel fundamental que desempenha no processo de desenvolvimento cultural da criança, sendo que nas práticas escolares se ensinam a desenhar letras e a construir palavras, mas não se ensina a linguagem escrita. A linguagem escrita é pouco estudada como um sistema particular de símbolos e signos cuja dominação é um ponto crítico em todo o desenvolvimento cognitivo e cultural da criança.

Do ponto de vista pedagógico, as estratégias utilizadas para ensinar a escrita não permitem a observação dessa transição, mas afirma-se que o desenvolvimento da linguagem escrita na criança ocorre pelo deslocamento do desenho de coisas para o desenho de palavras, 
é necessário que o ensino esteja organizado de forma que a leitura e a escrita se tornem significativas para as crianças e seu uso tenha relevância no contexto.

Por outro lado, o aspecto social, destacada é o sociólogo Bernstein (1984), que descreve dois conceitos teóricos que podem contribuir de forma significativa para a análise de práticas docentes no que se refere ao conteúdo sendo a classificação e estrutura. Para ele, classificação se refere às relações entre os conteúdos do currículo, em especial, a diferenciação entre conteúdos: quanto mais forte ou muito marcada a classificação, mais os conteúdos se isolam uns dos outros e quanto mais débil ou flexível a classificação, as fronteiras são menos marcadas, menos nítidas.

Em sua contraposição, a estrutura se refere ao contexto em que se comunica o conhecimento, à clareza com que se distingue o que pode ser e não pode ser comunicado: estrutura forte, quando é mínimo o grau de controle de professores e estudantes sobre a situação pedagógica e estrutura fraca, quanto maior a autonomia de docentes e alunos sobre a situação pedagógica.

Esses conceitos remetem análises das práticas docentes quanto a relevância da organização curricular e sua aplicabilidade junto aos discentes que estão em seus processos de escolarização, especificamente na construção da leitura e escrita.

\section{CONSIDERAÇÕES FINAIS}

Com base nas argumentações, pode-se afirmar que as recomendações oficiais em relação a organização curricular e as adoções de procedimentos didáticos são gerais e pouco operacionais; logo o aprendizado da leitura e escrita é a base em que se assenta todo o ensino posterior e que pouco tem se investigado sobre esse tema; nesse sentido, parece haver um conflito entre as práticas pedagógicas atualmente em uso (atividades individuais e em grupos, cópias para responder questões sem possibilidade de argumentação, produções de textos, sem significados sociais para o estudante e o educador; controle de ações dos professores sob seus alunos) negando a formação para a cidadania, a autonomia e desconsiderando as diferenças do capital cultural de cada aluno, bem como suas características cognitivas e de aprendizagens. 


\section{Revista Triângulo}

ISSN 2175-1609

As cenas descritas são apenas uma amostra de um ano de pesquisa realizada, mas evidenciam que as estratégias utilizadas em sala de aula por professores que se dizem inclusivos, não se diferenciam para os alunos, deixando-os como únicos em suas diferenças, negando potencialidades e limitações, excluindo as variedades existentes dos conhecimentos pedagógicos essenciais e necessários para possibilitar letramento para todos os estudantes.

Considera-se ainda que não basta formação acadêmica aos professores para que incentive a aprendizagem de todos os alunos, mas sim a tomada de consciência que há necessidade de que o professor realize mediação adequada, sendo esse observador crítico e estudioso de sua prática, com o intuito de aprimorar sua atividade profissional, potencializando o desenvolvimento e a aprendizagem para todos os envolvidos no processo de escolarização.

Os dados motivam para novas investigações referentes aos estilos de ensino dos professores, a identificação de práticas pedagógicas, a aprendizagem, as mediações, e, ainda, identificar o desenvolvimento de processos individuais com mediações coletivas negando suas características individuais, entre tantas outras indagações.

\section{REFERÊNCIAS}

BRASIL. Lei n. 9394/1996, que institui as Diretrizes e Bases da Educação Nacional. Brasília: MEC/SEESP, 1996.

BRASIL, Ministério da Educação. Secretaria de Educação Especial. Parâmetros curriculares nacionais: adaptações curriculares. Brasília: MEC/SEESP, 1998.

BRASIL, Ministério da Educação. Secretaria de Educação Especial. Programa de capacitação de recursos humanos: deficiência intelectual. Brasília: MEC/SEESP, 1997.

BRASIL. Ministério da Educação. Secretaria de Educação Especial. Deficiência intelectual (Atendimento educacional especializado). Brasília: MEC/SEESP, 2007.

BARDIN, Laurence. Análise do conteúdo. Lisboa: Edições 70, 1994.

CARVALHO, Rosita Edler. Removendo barreira para aprendizagem educação inclusiva. Porto Alegre: Mediação, 2000.

CARVALHO, Giselda Benedita Jordão De. O diagnóstico da deficiência intelectual no contexto de inclusão: uma proposta de avaliação psicopedagógica contextualizada e interventiva. Brasília: UnB, Dissertação de Mestrado 2001. 
CARVALHO, Rosita Edler. Removendo barreira para aprendizagem educação inclusiva. Porto Alegre: Mediação, 2004.

CONFERENCIA MUNDIAL SOBRE NECESSIDADES EDUCATIVAS ESPECIAIS. Declaração de Salamanca, e linha de ação sobre necessidades educativas especiais. Salamanca: UNESCO/Ministerio de Educación y de la Ciencia, 1994.

FERREIRO, Emília. Reflexões sobre alfabetização. 20. ed. São Paulo: Cortez, 1995.

GONZALEZ, Eugênio. Necessidades educacionais específicas. Porto Alegre: Artmed, 2008.

PACHECO, José. Caminhos para inclusão: guia para o aprimoramento da equipe escolar. Porto Alegre: Artes Médicas, 2007.

SOARES, Magda. Linguagem e escola: uma perspectiva social. 17. Ed. São Paulo: Ática, 2001.

Letramento: um tema em três gêneros. Belo Horizonte: Autêntica, 1998.

TFOUNI, Leda Verdani. Adultos não alfabetizados: o avesso do avesso. Campinas: Pontes, 1988.

VIGOTSKI, Lev Semyonovich. A formação social da mente: o desenvolvimento dos processos psicológicos superiores. 5. ed. São Paulo: Martins Fontes, 1997. (1984; 1989; 1994) 